\title{
NIÑOS, LIBROS Y MUNDOS: UNA PROPUESTA DE INNOVACIÓN
}

Patricia Levin y Silvia Przetycki

\section{INTRODUCCIÓN}

Dado que en la institución en la cual ejercemos nuestra tarea docente, Escuela Integral Hebreo Uruguaya, existe una biblioteca cuyo funcionamiento es muy bueno para el área nacional, a la cual los alumnos concurren con los docentes a realizar variadas actividades (y también en forma libre y espontánea, en los horarios de recreos), es nuestra preocupación, como docentes del área judaica, rescatar ese espacio y potenciarlo como ámbito de privilegio para el desarrollo de la cultura judía.

Nuestro interés consistió en realizar una innovación en dicho campo. Para ello contextualizamos el espacio físico y realizamos una propuesta de actividades relacionadas con el libro, para fomentar el desarrollo de la cultura judaica. Esta propuesta se llevó a cabo en el primer nivel de primaria (primeros y segundos años) conformados por un total de noventa y nueve alumnos.

Fuimos responsables de la tarea de planificación de las actividades, junto a las docentes encargadas de los grupos ya mencionados. El paradigma interpretativo - crítico se constituyó en eje de nuestra pesquisa. En función de esta postura ideológica fuimos seleccionando instrumentos coherentes con el modelo definido.

\section{CONTEXTUALIZACIÓN}

\subsection{Características de la E.I.H.U.}

E.I.H.U.- Escuela Integral Hebreo Uruguaya. El Centro Educativo en el cual realizamos nuestra tarea docente, fue fundado por un grupo de padres en 1961 con la idea de ofrecer una cultura general de muy buen nivel y una cultura judía propia. La Institución está ubicada en un barrio residencial de la costa capitalina.

La población es de 900 alumnos de los cuales 300 corresponden a Primaria; las familias pertenecen a un nivel socio - cultural medio y medio alto. Se trata de un colegio trilingüe (español - hebreo inglés), cuyos alumnos asisten en doble horario desde los cuatro años. La Institución está abocada a una innovación educativa cuya meta es mejorar la calidad de la educación buscando niveles de excelencia académica, tanto en el área nacional como en el área de educación judía.

\subsection{Descripción de la biblioteca}

Cuando se ingresa al Instituto, luego de atravesar la puerta principal y una pequeña recepción, se encuentra un ámbito de dos pisos, utilizado actualmente como BIBLIOTECA. La planta baja es de forma rectangular y la planta alta balconea en forma ovalada a la planta baja.Este espacio físico fue pensado como gimnasio en un primer momento, acondicionado luego como anfiteatro, para lo que se le hicieron algunas reformas (se bajó el piso, se construyó un escenario circular moqueteado y se instalaron butacas); después de varios años se empezó a utilizar como Templo (Sinagoga). 


\subsection{Situación actual de la biblioteca en el área judaica}

Nosotras como docentes del área judaica estamos preocupadas por la no utilización de este ámbito en nuestra tarea educativa, teniendo en cuenta la importancia de la lectura en la formación y desarrollo del potencial creativo del niño.

Desde el inicio del año lectivo 1997, una docente contratada por la institución asiste en el horario de ocho a once horas, cuatro veces por semana. Clasifica los libros por temas, procede al descarte de los que, por ser muy viejos o estar en mal estado, no van a interesar a alumnos y docentes.

La labor que está realizando la docente surgió a raíz de la preocupación por parte de la dirección de hebreo de la necesidad de conocer el material existente. Esta tarea de clasificación aún no ha concluido.

\section{MARCO TEÓRICO}

Para llevar adelante nuestra propuesta necesitamos definir algunos términos: como por ejemplo: Lectura, Biblioteca Escolar y Transmisión de Cultura judía.

\subsection{Lectura}

El lenguaje oral y escrito constituye un proceso complejo, que trae consigo experiencias, a veces enriquecedoras y otras frustrantes. La participación activa de padres y educadores es fundamental y decisiva a la hora de aprender a leer. Bibliotecas, librerías y medios de comunicación también desempeñan un rol importante.

Con respecto a este tema, F. Smith (1990) dice que la lectura implica comprensión de un texto y no la decodificación de las letras para convertirlas en fonemas (esto es reconocimiento de palabras). Comprender no sólo significa extraer información del texto; según el autor "los lectores fluidos en todos los aspectos de la lectura, son aquellos que atienden solamente a la información escrita relevante para sus propósitos" (1990:131) porque todo lector en el contacto visual con el material escrito selecciona la información que le interesa.

Lo esencial de la habilidad de la lectura es la información no visual que contribuye al proceso desde el interior de nuestra cabeza.

Lo que el autor refiere es: "la lectura asociada a la comprensión se convierte en la práctica de responder a preguntas que uno se formula" (1990:132). El niño comienza reconociendo señales y materiales del medio que lo rodea, que tienen sentido para él. Así irá comprendiendo en forma paulatina que hay diferencias entre los distintos signos impresos y que existe una relación entre el lenguaje impreso y el hablado.

El proceso de la lectura es predecir y buscar respuestas a las preguntas; la situación dependerá de las preguntas que nos planteamos internamente en base a la información que buscamos. No sólo somos inconscientes de las preguntas que nos van surgiendo al leer, sino también de las respuestas que elaboramos a partir del texto. Esto constituye el fundamento en la actividad lectora. Los adultos juegan un papel fundamental como asesores del niño en darle sentido a lo escrito. La disposición de la familia hacia las ideas, los libros y la lectura será el primer paso para la inclinación perdurable por la misma. Cuando la madre, el padre, los abuelos cuentan un cuento, están introduciendo al niño al mundo mágico de las palabras. Contar cuentos crea un nexo afectivo; el aprendizaje supone un replanteo de esos vínculos. De ahí la importancia de lo que se pone en manos del niño. El material de lectura debe ser interesante, atractivo y estar en buenas condiciones.

56 - Universidad ORT Uruguay 


\subsection{Biblioteca Escolar}

En la actualidad, la biblioteca es un componente integral del programa escolar actuando como fuerza educativa en sí misma. Ha ampliado su disposición de materiales incorporando los audiovisuales, didácticos, etc., para lograr un acercamiento a los conocimientos de una forma más dinámica y atractiva.

Una biblioteca que acompase los cambios de nuestro tiempo constituye un verdadero centro de recursos, dando lugar de esta forma a ese crecimiento personal al que aspiramos.

Con respecto a los objetivos que deben cumplir las bibliotecas escolares enumeraremos algunos de los puntos más destacables a nuestro entender:

- Crear un ambiente que estimule el uso libre y agradable del libro.

- Promover un lugar para el aprendizaje informal, que le permita practicar sus habilidades lectoras, distinto al salón de clase.

- Ofrecer materiales diversos que sirvan para desarrollar su espíritu de observación y avivar su curiosidad.

- Contribuir a la formación de un lector autónomo en su capacidad de selección, crítico y creativo en relación con la lectura.

- Brindar a los docentes programas de actualización en relación con la promoción de la lectura, educación en el uso de la información, producción y manejo de materiales educativos.

- Estimular el sentido de responsabilidad desarrollando en los alumnos actitudes tales como las de compartir un patrimonio común y respetar los derechos ajenos.

"La biblioteca escolar es una institución del sistema social que organiza materiales bibliográficos, audiovisuales y otros medios y los pone a disposición de una comunidad educativa. Constituye parte integral del sistema educativo y comparte sus objetivos, metas y fines. La biblioteca escolar es un instrumento de desarrollo del currículo y permite el fomento de la lectura y la formación de una actitud científica, constituye un elemento que forma al individuo para el aprendizaje permanente, fomenta la creatividad, la comunicación, facilita la recreación, apoya a los docentes en su capacitación y les ofrece la información necesaria para la toma de decisiones en el aula. Trabaja también con los padres de familia y con otros agentes de la comunidad". (De León, G. y otros, 1996:12).

\subsection{Judaísmo. Transmisión. Continuidad}

La preocupación por la continuidad del judaísmo ha estado siempre latente en el seno del pueblo judío. Desde todas las épocas ha sido preocupación que nuestra herencia espiritual sea transmitida y continúe de generación en generación.

De acuerdo con la filosofía del Instituto en el cual trabajamos, los programas del área judaica apuntan al dominio de la lengua hebrea como nexo entre todos los judíos del mundo, pero fundamentalmente a la transmisión de la historia, tradiciones, cultura, identidad y valores, fortificando los lazos que nos unen con la Tierra y el Estado de Israel.

Desde siempre, los líderes espirituales del pueblo judío se han preocupado por asegurar la continuidad y mantener los tesoros espirituales que fueron transmitidos en forma oral de padres a hijos, como una fuerza de unión dentro del judaísmo. Por intermedio de los relatos, se conectan las generaciones y se entreteje la trama de la cultura. En los relatos están nuestras raíces y a través de ellos nos comunicamos. 
Hemos recurrido a nuestra fuente: "LA BIBLIA", para fundamentar como ya desde épocas remotas se jerarquizaba la transmisión como nexo comunicativo.

“...Y se lo repetirás a tus hijos y se los dirás..."

Deuteronomio, capítulo 6, versículo 7.

“...Le dirás a tus hijos en ese día..."

Éxodo, capítulo 13, versículo 8.

Aquí se resalta uno de los principios del judaísmo, la transmisión a las futuras generaciones de cultura, valores y tradiciones para la continuidad de nuestro pueblo.

Al poner en contacto al niño con relatos, historias, narraciones, conviene tener en cuenta los factores emocionales del aprendizaje, para suscitar en él una actitud particular hacia las figuras y mensajes que aquellos representan. Es de gran valor cultural familiarizar al niño con el relato en su lenguaje original. Sin embargo, en el caso de los cuentos de la Biblia, el lenguaje propio de ella es demasiado difícil para la comprensión infantil, por lo cual la narración literal de los relatos corre el riesgo de no ser entendida y no lograr el objetivo propuesto. Por lo tanto, conviene narrar el relato en un lenguaje sencillo y más accesible para el niño, intercalando expresiones idiomáticas tomadas del lenguaje de la Biblia.

El conocimiento de los relatos fundamentales de la cultura del pueblo judío se acompañará así de un compromiso personal. Nuestra función educativa hoy, como docentes del área judaica, es continuar por este camino basándonos en la transmisión de la literatura para forjar en el niño bases sólidas en sus comienzos como ser judío.

\section{OBJETIVOS DE LA PROPUESTA}

\section{General:}

A través de este trabajo intentaremos implementar, en un ámbito físico ya existente dentro de la Institución, una propuesta educativa para el área judaica.

\section{Específicos:}

Poner al alcance, del mayor número posible de niños, materiales de lectura en el área judaica, de buena calidad, ajustados a sus intereses y competencia lectora, fomentándolo a través del trabajo a realizarse en la Biblioteca.

- Concebir la Biblioteca Escolar como un espacio para la difusión de la cultura judía.

- Reflexionar sobre los resultados obtenidos en esta innovación para luego generar estrategias a ser implementadas en el año siguiente.

\section{CAMPO DE ACCIÓN}

Nuestra idea es que este centro de recurso sea organizado por la misma maestra de clase, interactuando con sus pares e implementándolo en el primer nivel (primeros y segundos años). Por lo tanto la población involucrada son cinco grupos, tres de primer año y dos de segundo año, siendo la población total de noventa y nueve niños.

58 - Universidad ORT Uruguay 


\section{LA PROPUESTA PROPIAMENTE DICHA}

Nuestro proyecto de innovación consistirá en la explotación de la Biblioteca como otro centro de recurso para el aprendizaje, es decir la incorporación en la currícula de la asistencia semanal a la misma.

Elegimos la Biblioteca en nuestra propuesta de innovación, como otro centro de recurso para el aprendizaje porque:

- Está ubicada en un lugar estratégico dentro de la institución.

- Posee diversos materiales.

- Es un ambiente agradable.

- Estimula el deseo de tomar un libro para leer.

- Exhibe paneles con información de actividades a desarrollarse.

Fotos de actividades ya realizadas.

Distintos trabajos de los niños.

Para la contextualización de nuestra propuesta, nos parece importante generar un ámbito con:

- carteleras en hebreo.

- posters de temática judaica.

- música en hebreo.

- material bibliográfico, en hebreo, al alcance de los usuarios.

- brindar noticias sobre acontecimientos que ocurren en el área judaica.

· información general sobre Israel.

Las actividades que propondremos estarán relacionadas con El Libro:

- Lectura de un libro.

- Narración de un cuento.

- Representación de una obra de teatro basada en un cuento.

- Invitación a padres o abuelos para contar un cuento.

- Narración, por parte de los niños, de un libro leído en casa.

- Creación de la tapa de un libro.

- Invención de un cuento.

- Realización de una obra de títeres adaptando un cuento.

- Invitación a un periodista del periódico "Semanario Hebreo" en Uruguay.

- Invitación a un escritor de cuentos sobre temática judía.

- Otras. 


\section{METODOLOGÍA}

En todo trabajo de investigación o de innovación hay que optar por una metodología para poder desarrollar el proyecto en cuestión. Entendemos por metodología el conjunto de recursos o de instrumentos para llevar adelante algo; es el modo en que enfocamos los problemas y buscamos las respuestas.

Nuestro propósito es realizar una innovación en la biblioteca del Instituto, en el primer nivel del área judaica. Para ello, optamos por la perspectiva cualitativa, entendiéndose como tal a la investigación que produce datos descriptivos como son: las conductas observables y las propias palabras de las personas.

La observación participante y la entrevista son instrumentos metodológicos coherentes con el paradigma cualitativo, ya que se basan en la presencia prolongada del investigador en el contexto de la investigación - innovación para poder captar la mayor información e interpretar de forma más adecuada las interacciones y las situaciones. En este sentido se podría considerar a los investigadores cualitativos como naturalistas.

Todo investigador inicia su trabajo cuando decide qué va a investigar y por qué motivos ha de hacerlo. Para realizar una investigación o una innovación hay que partir de un momento en el cual se viven situaciones problemáticas de incoherencia entre lo que nos proponemos y la realidad. Es decir, que partimos de la clarificación de un problema inicial, sobre el que habremos de trabajar, recabando información para luego formular en sí mismo el problema a investigar o innovar.

\subsection{Instrumentos de recolección de datos}

Teniendo en cuenta que en nuestra innovación haremos uso de una metodología cualitativa, optaremos por la recolección de datos primarios que surgen del contacto directo con la realidad mediante la observación participante. También utilizaremos la entrevista como una forma específica de interacción social.

\subsection{Observación participante}

El investigador logrará obtener información variada, completa y confiable ya que los hechos se observan en el momento que se producen y tal como se producen. Siguiendo a Taylor y Bogdan (1986:31): "La observación participante es empleada para designar la investigación que involucra la interacción social entre el investigador y los informantes en el medio de los últimos, y durante la cual se recogen datos de modo sistemático y no intrusivo".

La observación implica que el investigador se involucre directamente con la actividad objeto de la observación, lo que puede variar, desde una integración total al grupo, o ser parte de éste durante un período. En nuestro caso, realizaremos observaciones de las diferentes actividades en la Biblioteca, en las que intentaremos registrar datos de valor. En cuanto a los datos a registrar, adoptaremos una posición flexible anotando las impresiones generales y espontáneas, detallando los aspectos de la observación según las necesidades y posibilidades. Nos referimos a una observación no estructurada.

\subsection{Entrevistas}

Otra técnica de la que haremos uso en nuestra investigación, como instrumento de metodología cualitativa, es la entrevista, teniendo en cuenta que ésta es una forma específica de interacción social.

60 - Universidad ORT Uruguay 
Es un diálogo asimétrico, especial, en el cual un individuo busca obtener información y el otro es el que la proporciona.

Toda la información que se obtiene a través de este instrumento es muy subjetiva. Las entrevistas pueden clasificarse según su grado de estructuración o formalización en estructuradas o formalizadas $y$ en informales o no estructuradas.

En nuestro proyecto de innovación realizaremos entrevistas semi - estructuradas, con ciertas pautas que guíen al entrevistado hacia los puntos de interés que deseamos obtener. El entrevistador es un recolector de datos; su trabajo consiste en que los sujetos se sientan lo suficientemente cómodos para responder a las preguntas. Se debe partir de preguntas de carácter general para ordenar la conversación.

De esta forma se obtiene un diálogo profundo y rico, captando no sólo las respuestas sino también las actitudes, los valores, y los pensamientos del entrevistado. Las entrevistas y las observaciones son procedimientos complementarios. Ambos pueden ser utilizados tratando de compensar sus ventajas y desventajas logrando información más amplia.

\section{DESARROLLO DE LA PROPUESTA}

Como ya hemos señalado, optamos por la observación participante y la entrevista como instrumentos metodológicos coherentes con el paradigma cualitativo, ya que se basan en la presencia prolongada del investigador en el contexto de la investigación - innovación para poder captar la mayor información y poder interpretar en la forma más adecuada las interacciones y las situaciones que se desarrollan.

\subsection{Las observaciones}

Para poder registrar los datos de la innovación, recurrimos a la técnica de la observación participante. Realizamos observaciones de diferentes actividades, llevadas a cabo en la Biblioteca del Instituto.

En ellas, nuestro centro de atención estuvo dirigido a la totalidad del grupo (alumnos y docentes). En algunas ocasiones participaron de las actividades invitados, coordinados anteriormente, como por ejemplo, un abuelo, una abuela y una madre. También observamos actividades en las cuales el docente trabajaba con el grupo. Las observaciones fueron realizadas en el período comprendido entre los meses de octubre y noviembre. Fueron un total de cinco observaciones, una a cada uno de los grupos participantes en el proyecto.

En cuanto a los datos a registrar adoptamos una posición flexible, tomando nota de las impresiones generales y espontáneas, detallando aspectos relevantes. Los medios de registro que utilizamos fueron notas de campo detalladas.

Las actividades observadas fueron:

- Invitación a un abuelo de una niña de segundo año para narrar un cuento de temática judía.

- Invitación a una abuela de una niña de segundo año para leer un libro.

- Invitación a una madre de un niño de primer año para leer un libro.

- Creación de un libro en hebreo, basándose en uno ya leído, con los alumnos de primer año.

- Actividad de lectura libre en hebreo, en la que los niños de primer año tenían la opción de elegir un libro y leerlo libremente. 


\subsection{Las entrevistas}

Seleccionamos esta técnica porque nos permite profundizar sobre algunos tópicos relevantes del tema a innovar, que no surgen de las observaciones antes realizadas. Las entrevistas se realizaron a cuatro docentes y a doce alumnos.

Dadas las características de nuestra innovación, consideramos apropiado agrupar a los entrevistados en dos grupos:

1) Los docentes.

2) Los alumnos.

\subsubsection{Entrevistas a los docentes}

Éstas se realizaron en forma individual, en la sala de maestros, en el mes de diciembre, una vez finalizadas las clases del año lectivo 1997; fueron grabadas, para lograr un diálogo fluido y fiel entre el entrevistador y el entrevistado.

Las docentes entrevistadas fueron cuatro, las participantes en el proyecto. Los grupos que pertenecen al primer nivel de primaria son cinco; una de las docentes trabaja en dos grupos. En las entrevistas realizadas se contemplaron los siguientes aspectos:

- Cooperación con el desarrollo de la cultura judía.

- Involucramiento con la propuesta de innovación.

- Importancia de la existencia de una biblioteca en el área judaica.

- Cambio de actitud frente a la lectura.

\subsubsection{Entrevistas a los alumnos}

Fueron entrevistados alumnos de todos los grupos del primer nivel de primaria; de cada grupo de segundo año tres alumnos y seis de los grupos de primer año. Un total de doce niños. Se seleccionaron, según el grado de participación e interés que demostraron en las actividades realizadas: los muy interesados y los poco interesados.

Las entrevistas se realizaron en forma individual, en la sala de maestros, durante la primer semana del primer mes de diciembre del año lectivo 1997. Los alumnos hablaron libremente, y no se sintieron influenciados por el rol del entrevistador, ya que se les explicaron los objetivos de este trabajo y su implementación. En esta ocasión, el registro utilizado fueron notas de campo detalladas. En las entrevistas los puntos de interés a destacar fueron:

- Concurrencia a la biblioteca.

- Jerarquización de actividades.

- Sentimientos y aportes. 


\section{ANÁLISIS DE LAS OBSERVACIONES}

A partir de los datos obtenidos en las diferentes observaciones realizadas en la Biblioteca, podemos puntualizar las siguientes consideraciones: mente elevado.

- El grado de participación e interés de los alumnos ante las diferentes actividades, es general-

- El docente integra mayoritariamente, las intervenciones y aportes de los alumnos, de forma natural.

- En todas las actividades, el docente estuvo atento al comportamiento de los alumnos, llamando la atención de aquellos que, momentáneamente, se dispersaban.

- En la mayoría de los casos, se da participación a los alumnos con la intención de conducirlos hacia el objetivo planteado por el docente.

- La actitud de los alumnos frente a la persona externa que intervino en la actividad, es de respeto y entusiasmo.

\section{ANÁLISIS DE LAS ENTREVISTAS}

\subsection{Los docentes}

Realizaremos el análisis del material empírico aplicando una aproximación cualitativa. En una primera instancia agruparemos los datos obtenidos en las diferentes entrevistas. Los resultados serán analizados según los puntos de interés ya mencionados. Finalmente relacionaremos la información recogida.

De las respuestas y opiniones emergentes de las cuatro entrevistas realizadas a los docentes, creemos que podemos destacar lo siguiente:

- Los docentes consideran que este proyecto coopera con el desarrollo de la cultura judaica. Al estar el niño tempranamente en contacto con literatura en dicha área, va desarrollando su identidad como ser judío, asegurando la continuidad y la transmisión de la historia, tradiciones, cultura y valores. Esto se conecta con el punto: "cooperación con el desarrollo de la cultura judía".

- En general, encontramos que los docentes respondieron en forma unánime, considerándose involucrados en el proyecto. Trabajaron con entusiasmo en el mismo, sintiéndose partícipes y portadores de las actividades.

- También sostienen que los alumnos se sintieron involucrados en el proyecto y que disfrutaron al participar de las actividades en la Biblioteca, ya que los docentes respondieron que a los niños: "les encantaba ir a la biblioteca", "pedían para ir", "les gustaba ir", "participaron de las actividades con entusiasmo", "exigían ir", "participaron con gusto", "aprenden sin darse cuenta", "es más recreativo", "querían ir", "disfrutaban".

- Integrado al punto: "involucramiento con la propuesta de innovación", los docentes responden que sería muy interesante y positivo que este proyecto comenzara desde principios del año lectivo 1998 y se extendiera a todos los grupos de primaria, desde primer año hasta sexto año. 
- Todos los entrevistados resaltaron la importancia de la existencia de una biblioteca para el área judaica, como pilar de la transmisión de la cultura. Teniendo en cuenta que es una escuela judía, el material para dicha área debe estar actualizado para consulta no sólo de alumnos, sino también de docentes y padres. Con su crecimiento y desarrollo, se fomentará un nexo comunicativo entre las distintas generaciones.

- Dos de los entrevistados, responden que notaron un cambio positivo frente a la lectura por parte de los niños; por el contrario los otros dos entrevistados si bien apreciaron "una mayor motivación e interés hacia los libros en hebreo" y "gusto e interés por las actividades en biblioteca", consideran que el cambio de actitud frente a la lectura será evaluado en un futuro.

\subsection{Los niños}

Del análisis de los datos obtenidos en las entrevistas, se desprende que todos los niños respondieron positivamente frente a la pregunta: ¿Te gusta venir con tus compañeros y maestra de hebreo a la Biblioteca?

Algunos, clarificando el porqué de su respuesta; por ej. "porque me gusta leer libros y que la morá (maestra), me cuente cuentos"; "porque había muchos libros en hebreo y nos sentábamos todos juntos en la alfombra"; "me gusta leer libros, de ellos aprendo mucho vocabulario".

Con respecto al interés que demostraron por las diferentes actividades, la mayoría de los alumnos se inclinaron por la preferencia hacia obras de teatro, leer libros, escuchar cuentos o historias. Dos niños respondieron que lo que más les agradó fue "hacer libros". En estos casos, ellos se manifestaron libremente, según su preferencia personal.

Con referencia al punto: sentimientos y aportes, podemos catalogar a los alumnos en dos niveles. En un primer nivel, los niños que respondieron: "no sentí nada" o "nada".

En un segundo nivel, estarían los niños que respondieron por ejemplo: "es muy sagrado", "son muy importantes los libros en hebreo", "me gustan las historias del pueblo judío", "es como tener los personajes al lado tuyo", "me sentí feliz", "sentí algo, no sé como decirlo", "sentí que era lindo", "me siento diferente cuando escucho un cuento en hebreo que en español", "aprender y escuchar".

A través del análisis de las entrevistas emerge, que los niños concurrieron a la biblioteca con entusiasmo y con una actitud positiva.

\section{REFLEXIONES}

Luego de haber analizado las observaciones y las entrevistas, creemos que estamos en condiciones de efectuar las siguientes reflexiones:

Con relación a los alumnos: podemos decir que la Biblioteca pone a disposición de los alumnos materiales de lectura de buena calidad; los mismos se ajustan a los intereses y capacidad lectora de los niños. Proporciona un ámbito motivador para la lectura, ya que los alumnos manifiestan mucho agrado por concurrir a la Biblioteca, afirmando que disfrutan de dichos momentos. La Biblioteca en el área judaica proporciona a los niños situaciones de aprendizaje exitoso e interacción positiva en lo grupal, para transmitir la cultura judaica y lograr un fortalecimiento de su identidad. 
Con relación a los docentes: todos los docentes participantes en el proyecto se sintieron involucrados en el mismo, ya que se realizaron reuniones de planificación e intercambio de ideas para desarrollar las actividades; apoyaron las iniciativas que fueron surgiendo y se mostraron muy entusiasmados. Los docentes entrevistados consideran la existencia de una Biblioteca para el área judaica, como fundamental para el fortalecimiento del desarrollo de dicha cultura.

Con relación a la institución: consideramos que ella apoya el proyecto, ya que la dirección demostró ser receptiva y colaboradora en todos los aspectos, favoreciendo la implementación de la innovación. Para la contextualización de nuestra propuesta, y la revalorización del espacio físico para el área judaica, tanto la institución como el equipo de Biblioteca nos proporcionó el ambiente físico adecuado, atendiendo las necesidades que iban surgiendo durante la innovación. Debemos destacar lo importante de las buenas relaciones humanas existentes entre los integrantes del equipo de docentes participantes en la innovación, los integrantes del equipo de biblioteca y la dirección. Esto facilitó la tarea.

Con relación a los objetivos: consideramos que la puesta en marcha de la Biblioteca de la Escuela Integral Hebreo Uruguaya para el área judaica, es altamente positiva en la gran mayoría de sus aspectos.

El objetivo general y los específicos se fueron cumpliendo durante la innovación, ya que se implementó la utilización de la Biblioteca para el área judaica. Se realizaron las actividades programadas, teniendo en cuenta los intereses de los niños y su competencia lectora, logrando a través del trabajo en Biblioteca la difusión de la cultura judía.

Sería nuestro mayor anhelo continuar con la propuesta para el año lectivo 1998.

\section{Bibliografía}

AMEIJEIRAS, C. 1994. Bibliotecas para los más pequeños. En: Revista Educación y biblioteca, No 6: 43-58. Barcelona, Dossier.

BARYLKO, J. 1993. Relatos para padres e hijos. Buenos Aires, Emecé.

BOURNEEUF, D.; PARÉ, A. 1989. Pedagogía y lectura: animación de un rincón de lectura. Bogo tá, Kapeluz.

CASTÁN LANASPA, G. 1995. Las bibliotecas escolares y el currículum de la ESO. En: Revista Aula de innovación educativa, No 43: 49-53. Barcelona, Graó Educación.

CASTRILLÓN, S.; VAN PATTEN de OCAMPO, M. 1982. Modelos flexibles para un sistema nacional de bibliotecas escolares. Bogotá, OEA.

CONSEJO CENTRAL DE EDUCACIÓN ISRAELITA. 1980. Relatos de la Biblia para el preescolar. Buenos Aires, Centro Pedagógico.

CONSEJO DE EDUCACIÓN PRIMARIA. 1986. Programa para Escuelas Urbanas. Montevideo, C.E.P.

COOK, T.D.; REICHARDDT, CH.S. 1986. Métodos cualitativos y cuantitativos en investigación evaluativa. Madrid, Morata.

DE LEÓN, G. et. alt. 1996. Reestructura organizativa y creación de Centros Locales del Proyecto de Centros de Recursos para el Aprendizaje (CRA) en el marco de las escuelas públicas del Depar tamento de Montevideo. Montevideo, EUCA.

DELGADO DE MIRANDA, R. 1984. La Biblioteca escolar central: manual para su organización y funcionamiento. Ciudad de Guayana, Banco del libro. 
HAMMERSLEY, M.; ATKINSON, P. 1994. Etnografía: Métodos de investigación. Barcelona, Paidós Básica.

IMBERNÓN, F. 1995. Innovación y formación en y para los centros. En: Revista Cuadernos de Pedagogía, No 240: 68-72. Barcelona, Fontalba.

KLIKSBERG, B. 1987. Tiene vigencia la cultura judía a fines del siglo XX. En: Revista Rum bos en el judaísmo, el sionismo e Israel, No 21:36-42. Jerusalem, Hamaccabi.

LORENZO, E. 1997. Lingüística y Didáctica. Buenos Aires, Colihue.

POSTIC, M.; DE KETELE, J. M. 1992. Observar las situaciones educativas. Madrid, Narcea.

RAVELLA, P. 1991. La institución educativa como eje para la estrategia de renovación. En: Revista Levántate y anda, No1: 16-19. Montevideo, UCUDAL.

REINA, C. 1960. La Santa Biblia. Antiguo y Nuevo Testamento. Montevideo, Sociedades Bíblicas.

SABINO, C. 1986. El proceso de investigación. Buenos Aires, Humanitas.

SMITH, F. 1990. Para darle sentido a la lectura. Madrid, Visor.

TAYLOR, S.; BOGDAN, R. 1986. Introducción a los métodos cualitativos de investigación. Buenos Aires, Paidós.

TRUEBA MARCANO, B. 1995. Organizar el espacio de la biblioteca para los más pequeños. En: Revista Educación y biblioteca, No 59: 63-65. Barcelona, Dossier.

WITTROCK, M. 1989. La investigación de la enseñanza, II. Métodos cualitativos y de obser vación. Barcelona, Paidós. 